\title{
BMJ Open Mental health associations with eczema, asthma and hay fever in children: a cross-sectional survey
}

\author{
Lene Hammer-Helmich, ${ }^{1,2}$ Allan Linneberg, ${ }^{1,3,4}$ Carsten Obel, ${ }^{5}$ \\ Simon Francis Thomsen, ${ }^{6,7}$ Line Tang Møllehave, ${ }^{1}$ Charlotte Glümer ${ }^{1,8}$
}

To cite: Hammer-Helmich L, Linneberg A, Obel C, et al. Mental health associations with eczema, asthma and hay fever in children: a crosssectional survey. BMJ Open 2016:6: 012637. doi:10.1136/bmjopen-2016012637

- Prepublication history for this paper is available online. To view these files please visit the journal online (http://dx.doi.org/10.1136/ bmjopen-2016-012637)

Received 18 May 2016 Revised 30 August 2016 Accepted 19 September 2016

CrossMark

For numbered affiliations see end of article.

Correspondence to Professor Charlotte Glümer; chgl@dadlnet.dk

\section{ABSTRACT}

Objective: This study aimed to examine the association of eczema, asthma and hay fever with mental health in a general child population and to assess the influence of parental socioeconomic position on these associations.

Methods: We conducted a cross-sectional health survey of children aged 3, 6, 11 and 15 years in the City of Copenhagen, Denmark. Individual questionnaire data on eczema, asthma, and hay fever and mental health problems assessed using the Strengths and Difficulties Questionnaire (SDQ) was linked to register data on demographics and parental socioeconomic position. 9215 (47.9\%) children were included in the analyses.

Results: Linear regression analyses showed that children with current eczema symptoms had higher SDQ scores (mean difference, $95 \% \mathrm{Cl}$ ) of emotional problems $(0.26,0.12$ to 0.39$)$, conduct problems $(0.19,0.09$ to 0.29$)$ and hyperactivity problems $(0.32$, 0.16 to 0.48 ); children with current asthma symptoms had higher SDQ scores of emotional problems $(0.45$, 0.32 to 0.58$)$, conduct problems $(0.28,0.18$ to 0.38$)$ and hyperactivity problems $(0.52,0.35$ to 0.69$)$; and children with current hay fever symptoms had higher SDQ scores of emotional problems $(0.57,0.42$ to $0.72)$, conduct problems $(0.22,0.11$ to 0.33$)$, hyperactivity problems $(0.44,0.26$ to 0.61$)$ and peer problems $(0.14,0.01$ to 0.26$)$, compared with children without current symptoms of the relevant disease. For most associations, parental socioeconomic position did not modify the effect.

Conclusions: Children with eczema, asthma or hay fever had more emotional, conduct and hyperactivity problems, but not peer problems, compared with children without these diseases. Atopic diseases added equally to the burden of mental health problems independent of socioeconomic position.

\section{INTRODUCTION}

Children with eczema (atopic dermatitis), asthma or hay fever may experience physical, psychological and social impairment ${ }^{1}{ }^{2}$ and atopic diseases are associated with a great health-related quality of life burden. ${ }^{3}$ It is,

\section{Strengths and limitations of this study}

- The study population was large, comprising 9215 children.

- We used validated questionnaires to measure atopic diseases and mental health problems.

- Full information on socioeconomic position was available from reliable national registers.

- The cross-sectional design prevents us from determining causality.

- A risk of non-response bias remains, despite weighing for non-response, as the response rate was $47.9 \%$.

however, less clear if childhood atopic diseases are related to mental health problems.

For asthma, an association with internalising problems (ie, anxiety and depressive symptoms) has been shown, ${ }^{45}$ whereas evidence of a relation with externalising problems (ie, oppositional and hyperactive symptoms) is less clear. ${ }^{56}$ In a meta-analysis of 26 observational studies, McQuaid found increases in internalising and externalising problems for children with asthma compared with children without asthma. ${ }^{5}$

For children with eczema, a single study found increased likelihood of both emotional problems and conduct problems compared with children without eczema. ${ }^{7}$ Two small studies found no association between hay fever and mental health problems. ${ }^{8} 9$ More specific information is needed regarding the types of mental health problems associated with atopic diseases in children, especially concerning eczema and hay fever.

Socioeconomic position (SEP) has been suggested as the underlying factor explaining the association between atopic diseases and mental health problems, ${ }^{5}$ but, due to limited demographic information in most studies, this hypothesis has scarcely been explored. Moreover, to the best of our knowledge, no studies have addressed the issue of 
socioeconomic disparities in the mental health consequences of atopic diseases among children.

This study aimed to examine the association of eczema, asthma and hay fever with mental health in a general child population and to assess if these associations were modified by parental SEP.

\section{METHODS}

\section{Study population and design}

This study was based on a cross-sectional child health survey, conducted in the City of Copenhagen in the autumn of 2009, which is described elsewhere. ${ }^{10}$ The primary carers of all children born in 1994, 1998, 2003 or 2006, that is, children aged 15, 11, 6 or 3 years, resident in the City of Copenhagen in September 2009, received a questionnaire concerning health, lifestyle, symptoms and diseases. They were asked to respond for children aged 3 or 6 years, whereas children aged 11 or 15 years were asked to respond themselves. The parents gave informed consent for participation in research projects when returning the questionnaires.

Questionnaire data were linked to data from national registers on demographics, education and income for both parents and their present partners. These data were provided by Statistics Denmark using the unique personal identification number, the central person register (CPR)-number. ${ }^{11}$ The association between atopic diseases and the covariables has been published elsewhere. ${ }^{10}$

In total, 9720 of the 19241 invited children responded $(50.5 \%)$. Children aged 15 years had the lowest response rate $(42.4 \%)$ followed by children aged 11 years $(50.9 \%), 6$ years $(51.0 \%)$ and 3 years $(55.2 \%)$. Of the respondents, 9215 had information on at least one atopic disease and one mental health problem and were included in this study. Missing values among the 9215 children ranged from 0 to 276 for each variable, highest for measures of atopic diseases ever, and lowest for current atopic symptoms. There were no missing values for the SEP measures.

\section{Mental health problems}

Mental health problems were measured by the Strengths and Difficulties Questionnaire (SDQ). The SDQ consists of 25 items with three response options: not true, somewhat true or certainly true. The items can be grouped into five subscales of five items each: emotional problems, conduct problems, hyperactivity problems, peer problems and prosocial behaviour. ${ }^{12}$ We used the four problem subscales to define mental health problems. The subscales are each scored according to the manual (http://www.sdqinfo.com/) obtaining continuous scores from 0 to 10 , with higher scores indicating greater problems and increased odds of mental disorder for each one-point increase on the scale. ${ }^{13}$ In addition, cut-off scores for each subscale have been established in several countries, categorising the $80 \%$ of a child population with the lowest scores as 'normal', the next $10 \%$ as 'borderline' and the $10 \%$ with the highest scores as 'clinical' or 'abnormal'. The borderline cut-off scores are recommended when high sensitivity is desired, and the abnormal cut-off scores are recommended when high specificity is desired. ${ }^{12}$ We used the Danish abnormal cut-off scores to create dichotomous measures of mental health problems. ${ }^{14}$

\section{Eczema, asthma and hay fever}

Questions on atopic diseases were adapted from the International Study of Asthma and Allergies in Childhood (ISAAC). ${ }^{15}$ Measures of eczema, asthma and hay fever were discerned as 'known disease ever' and 'current symptoms'. Known disease ever was defined for each disease as 'Yes' to the question: 'Have you (your child) ever had...(childhood eczema/asthma/hay fever)?'; current asthma symptoms as 'Yes' to: 'Have you (has your child) had wheezing or whistling in the chest in the past 12 months?'; and current hay fever symptoms as 'Yes' to: 'In the past 12 months, have you (has your child) had a problem with sneezing or a runny or blocked nose when you (he/she) did not have a cold or the flu?'. We defined current eczema symptoms according to the UK Working Party's Diagnostic Criteria ${ }^{16}$ as 'Yes' to both questions: 'Have you (has your child) ever had an itchy rash which was coming and going for at least 6 months?' And 'Have you (has your child) had this itchy rash at any time in the last 12 months?' and at least two of the following: (1) location at the folds of the elbows, behind the knees, in front of the ankles, under the buttocks, or around the neck, ears or eyes; (2) onset before the age of 2 years; (3) a tendency of dry skin and (4) a personal history of atopic disease.

\section{Socioeconomic factors}

The socioeconomic measures were derived from register data. The primary carer was defined as the mother, except when the father has full custody of the child.

The primary carer's highest attained education as of October 2009 was divided into four categories: (a) primary/secondary school, including lower secondary school and general upper secondary education; (b) vocational education and training; (c) academy or bachelor's degree and (d) master's or PhD degree.

Income was calculated as the total household income minus taxes and interest expenses, divided by the Organisation for Economic Co-operation and Development (OECD) equivalent size of the household with a weight of 1.0 to the first adult, 0.5 to any other person aged $14+$ years, and 0.3 to each child $<14$ years. The study households were divided into four income quartiles, corresponding to around: (a) <€21 800; (b) €21 800-€27 500; (c) >€27 500-€35 000 and (d) $>€ 35000 /$ year. 


\section{Statistical analyses}

Raw mean values were given for each SDQ subscale in total and for subgroups of children. The associations between atopic disease as exposure and continuous scores of mental health problems as outcomes were analysed by linear regression analyses using maximum likelihood estimation, adjusted for gender, age and the primary carer's educational level. Additional adjustments for household income along with the other potential confounders were made in separate analyses.

Effect measure modification between parental SEP and atopic disease was assessed for all SDQ scales by entering an interaction term in the model statement of each regression analysis and testing this term with a maximum likelihood test. Joint effect measures were estimated and presented for associations with a $\mathrm{p}$ value $<0.05$.

The associations between atopic disease and abnormal SDQ scores of mental health problems were analysed by logistic regression analyses, again using maximum likelihood estimation and adjusting for gender, age and primary carer's educational level. Additional adjustments for household income were made in separate analyses.

Since complete case analyses were performed, the number of participants included in the analyses may differ.

Responders were more often female, younger and primary carers had longer educations compared with non-responders (data not shown). Data were weighted for non-response with weights computed by Statistics Denmark. Weights were based on register information concerning age, gender, ethnicity, health service use, type of residence, household income, parental educational level and parental civil status. ${ }^{17}$ All analyses were performed using the survey procedures of SAS statistical software (V.9.3, SAS Institute, Cary, North Carolina, USA).

\section{RESULTS}

\section{Characteristics of the children}

Girls had slightly higher scores of emotional problems than boys, whereas boys had higher scores of hyperactivity problems than girls (table 1 ). The score of emotional problems increased with increasing age, whereas children aged 15 or 3 years had higher scores of conduct problems, hyperactivity problems and peer problems than children aged 6 or 11 years. All problem scores increased with decreasing educational level of the primary carer and with decreasing household income.

\section{Atopic disease symptoms and mental health}

Children with any known atopic disease ever or current symptoms had slightly higher scores of emotional, conduct and hyperactivity problems than children without (table 1). The scores were highest among children with more than one disease or symptom group.
When adjusting for gender, age and the primary carer's educational level, we also found higher levels of emotional problems, hyperactivity problems and slightly higher levels of conduct problems among children with current symptoms of atopic disease compared with children without current symptoms of the relevant atopic condition (table 2). Peer problems, however, were only associated with current hay fever symptoms. Analyses of the known disease ever measures gave similar results, however, though less pronounced; adjusting for household income did not change the results (not shown).

We found socioeconomic disparities in mental health problems. Children with lower compared with higher educated primary carers experienced more mental health problems of all four types, regardless of symptoms of atopic disease, however, with a few exceptions. The association of current asthma symptoms with hyperactivity problems was stronger among children with low compared with highly educated primary carers (table 3 ). Among children of primary carers with primary or secondary school education, current asthma symptoms increased the hyperactivity problem score by almost 1 scale point (from 0.47 (95\% CI 0.33 to 0.62 ) to 1.34 (95\% CI 0.94 to 1.74$)$ ). Among children of primary carers with a master's or PhD degree, this difference was only 0.27 (95\% CI 0.01 to 0.53 ).

However, known eczema ever only increased the level of conduct problems among children with highly educated primary carers, whereas no association was found among children of primary carers with low education (table 3).

There was no other significant interaction between atopic disease and parental SEP for any SDQ scales (data not shown).

\section{Atopic disease symptoms and abnormal scores of mental health}

We found increased likelihood of abnormal scores of hyperactivity problems among children with any of the atopic symptoms compared with children without atopic symptoms, highest among children with asthma symptoms or symptoms of two or more diseases (table 4). Asthma and hay fever symptoms also increased the likelihood of abnormal scores of emotional problems. No association was found between any atopic disease and abnormal scores of peer problems. Children with primary carers with lower compared with higher educational level had substantially increased likelihood of abnormal scores of all four problem scales, regardless of symptoms of atopic disease (table 4).

\section{DISCUSSION}

We found that children with symptoms of eczema, asthma or hay fever, regardless of gender, age group and parental SEP, were more likely to have emotional, conduct and hyperactivity problems, compared with children without the atopic disease. The levels and risks 
Table 1 Characteristics of the children in relation to SDQ scores of mental health problems

\begin{tabular}{|c|c|c|c|c|c|c|c|c|c|}
\hline & \multirow[b]{2}{*}{$\begin{array}{l}\mathbf{N} \\
\text { Total }\end{array}$} & \multicolumn{2}{|c|}{ Emotional problems } & \multicolumn{2}{|c|}{ Conduct problems } & \multicolumn{2}{|c|}{ Hyperactivity problems } & \multicolumn{2}{|c|}{ Peer problems } \\
\hline & & $\begin{array}{l}\text { Mean score } \\
\text { (SD) }\end{array}$ & $\begin{array}{l}\text { Abnormal score } \\
\mathrm{N}(\%)\end{array}$ & $\begin{array}{l}\text { Mean score } \\
\text { (SD) }\end{array}$ & $\begin{array}{l}\text { Abnormal score } \\
\mathrm{N}(\%)\end{array}$ & $\begin{array}{l}\text { Mean score } \\
\text { (SD) }\end{array}$ & $\begin{array}{l}\text { Abnormal score } \\
\text { N (\%) }\end{array}$ & $\begin{array}{l}\text { Mean score } \\
\text { (SD) }\end{array}$ & $\begin{array}{l}\text { Abnormal score } \\
\mathrm{N}(\%)\end{array}$ \\
\hline Total & 9215 & $1.57(1.74)$ & $683(7.4)$ & $1.37(1.26)$ & $555(6.0)$ & $2.68(2.12)$ & $937(10.2)$ & $1.09(1.52)$ & $771(8.4)$ \\
\hline \multicolumn{10}{|l|}{ Gender } \\
\hline Female & 4655 & $1.77(1.84)$ & $424(9.1)$ & $1.33(1.20)$ & $228(4.9)$ & $2.45(2.00)$ & $382(8.2)$ & $1.02(1.45)$ & $335(7.2)$ \\
\hline Male & 4560 & $1.38(1.62)$ & $259(5.7)$ & $1.42(1.31)$ & $327(7.2)$ & $2.91(2.20)$ & $555(12.2)$ & $1.17(1.59)$ & $436(9.6)$ \\
\hline \multicolumn{10}{|l|}{ Age, years } \\
\hline 3 & 3292 & $1.13(1.38)$ & $94(2.9)$ & $1.41(1.17)$ & $163(5.0)$ & $2.76(1.92)$ & $295(9.0)$ & $0.93(1.46)$ & $246(7.5)$ \\
\hline 6 & 2378 & $1.53(1.73)$ & $172(7.2)$ & 1.18 (1.22) & $112(4.7)$ & $2.36(2.16)$ & 198 (8.3) & $0.89(1.51)$ & $185(7.8)$ \\
\hline 11 & 1949 & $1.81(1.85)$ & $180(9.2)$ & $1.37(1.35)$ & $143(7.3)$ & $2.54(2.16)$ & $197(10.1)$ & $1.35(1.56)$ & $196(10.1)$ \\
\hline 15 & 1596 & $2.27(2.01)$ & $237(14.8)$ & $1.58(1.34)$ & $137(8.6)$ & $3.14(2.27)$ & 247 (15.5) & 1.39 (1.52) & $144(9.0)$ \\
\hline \multicolumn{10}{|c|}{ Primary carer's education } \\
\hline Master & 2540 & $1.32(1.53)$ & $113(4.4)$ & $1.22(1.13)$ & $101(4.0)$ & $2.38(1.94)$ & $177(7.0)$ & $0.76(1.28)$ & $119(4.7)$ \\
\hline Bachelor & 3106 & $1.54(1.73)$ & $225(7.2)$ & $1.32(1.20)$ & $161(5.2)$ & $2.59(2.07)$ & $283(9.1)$ & $0.90(1.32)$ & $166(5.3)$ \\
\hline Vocational & 1725 & $1.76(1.84)$ & $161(9.3)$ & $1.45(1.34)$ & $124(7.2)$ & $2.99(2.23)$ & 237 (13.7) & $1.33(1.63)$ & $183(10.6)$ \\
\hline School & 1844 & $1.80(1.89)$ & $184(10.0)$ & $1.59(1.40)$ & 169 (9.2) & $2.95(2.24)$ & 240 (13.0) & $1.65(1.83)$ & $303(16.4)$ \\
\hline \multicolumn{10}{|l|}{ Household income } \\
\hline Upper quartile & 2356 & $1.38(1.61)$ & $135(5.7)$ & $1.23(1.14)$ & $88(3.7)$ & $2.47(2.06)$ & $200(8.5)$ & $0.81(1.27)$ & $106(4.5)$ \\
\hline Upper middle quartile & 2368 & 1.47 (1.69) & $151(6.4)$ & $1.28(1.19)$ & $127(5.4)$ & 2.54 (1.99) & $199(8.4)$ & $0.82(1.28)$ & $112(4.7)$ \\
\hline Lower middle quartile & 2306 & $1.67(1.77)$ & $186(8.1)$ & $1.45(1.28)$ & $149(6.5)$ & $2.84(2.18)$ & $264(11.4)$ & $1.10(1.49)$ & $187(8.1)$ \\
\hline Lower quartile & 2184 & $1.79(1.88)$ & $211(9.7)$ & $1.55(1.41)$ & $191(8.7)$ & 2.89 (2.22) & 274 (12.5) & $1.70(1.85)$ & $366(16.8)$ \\
\hline \multicolumn{10}{|l|}{ Eczema } \\
\hline Known disease ever & 1538 & $1.75(1.84)$ & $140(9.1)$ & $1.40(1.24)$ & $91(5.9)$ & $2.82(2.15)$ & $181(11.8)$ & $1.02(1.48)$ & $118(7.7)$ \\
\hline Current symptoms & 886 & $1.76(1.84)$ & 77 (8.7) & $1.52(1.29)$ & $60(6.8)$ & $2.88(2.09)$ & 103 (11.6) & $1.02(1.50)$ & 74 (8.4) \\
\hline \multicolumn{10}{|l|}{ Asthma } \\
\hline Known disease ever & 649 & $2.05(1.98)$ & $84(12.9)$ & $1.52(1.34)$ & $50(7.7)$ & $3.04(2.34)$ & $98(15.1)$ & $1.30(1.58)$ & 66 (10.2) \\
\hline Current symptoms & 1079 & $1.88(1.92)$ & $116(10.8)$ & $1.61(1.33)$ & $96(8.9)$ & $3.17(2.25)$ & $167(15.5)$ & $1.12(1.50)$ & $90(8.3)$ \\
\hline \multicolumn{10}{|l|}{ Hay fever } \\
\hline Known disease ever & 796 & $2.11(1.96)$ & $101(12.7)$ & $1.54(1.38)$ & $70(8.8)$ & $2.85(2.21)$ & $101(12.7)$ & $1.31(1.61)$ & $90(11.3)$ \\
\hline Current symptoms* & 1000 & $2.42(2.02)$ & $155(15.5)$ & $1.58(1.35)$ & $81(8.1)$ & $3.08(2.23)$ & $145(14.5)$ & $1.44(1.56)$ & $107(10.7)$ \\
\hline \multicolumn{10}{|c|}{ Known atopic disease ever } \\
\hline None & 6591 & $1.46(1.68)$ & $426(6.5)$ & $1.33(1.23)$ & $362(5.5)$ & $2.60(2.08)$ & $609(9.2)$ & $1.07(1.51)$ & $526(8.0)$ \\
\hline 1 & 1831 & $1.78(1.83)$ & $155(8.5)$ & 1.46 (1.32) & $133(7.3)$ & $2.86(2.16)$ & $221(12.1)$ & $1.14(1.55)$ & $171(9.3)$ \\
\hline 2 or more & 438 & $2.17(2.03)$ & $68(15.5)$ & $1.44(1.25)$ & $29(6.6)$ & $2.85(2.26)$ & $58(13.2)$ & $1.18(1.54)$ & $41(9.4)$ \\
\hline \multicolumn{10}{|c|}{ Current symptoms of atopic disease } \\
\hline None & 6603 & $1.42(1.64)$ & $400(6.1)$ & $1.30(1.22)$ & $340(5.1)$ & $2.55(2.07)$ & $589(8.9)$ & $1.05(1.52)$ & $531(8.0)$ \\
\hline 1 & 1981 & $1.87(1.90)$ & $191(9.6)$ & 1.55 (1.32) & $159(8.0)$ & $2.94(2.14)$ & $240(12.1)$ & $1.13(1.48)$ & $166(8.4)$ \\
\hline 2 or more* & 452 & $2.33(2.03)$ & $72(15.9)$ & $1.63(1.34)$ & 37 (8.2) & $3.32(2.32)$ & $82(18.1)$ & $1.34(1.62)$ & $48(10.6)$ \\
\hline
\end{tabular}


Table 2 Mental health problems among children with eczema, asthma and hay fever compared with children without

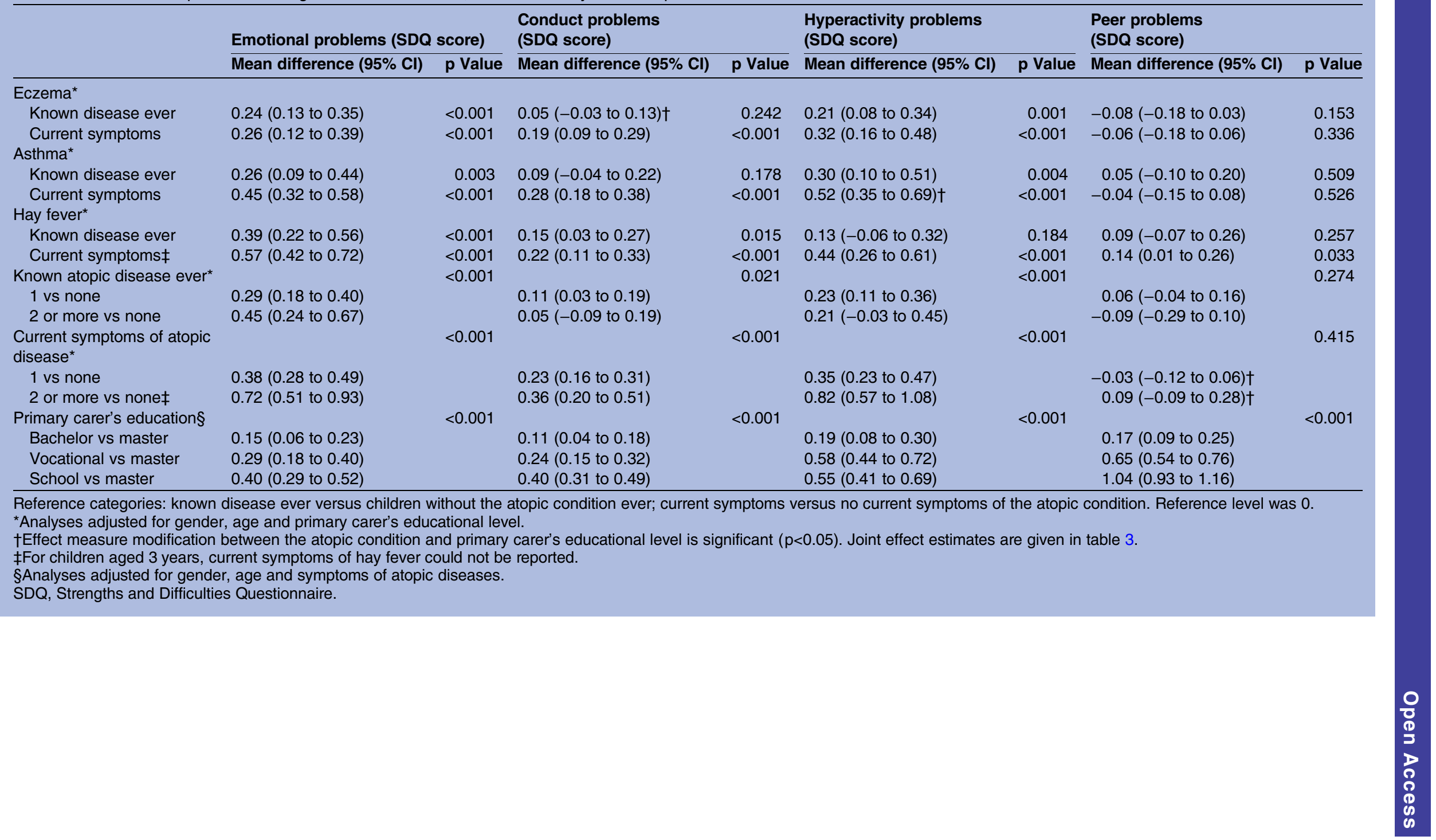

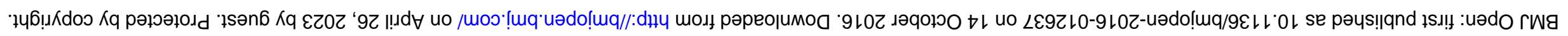




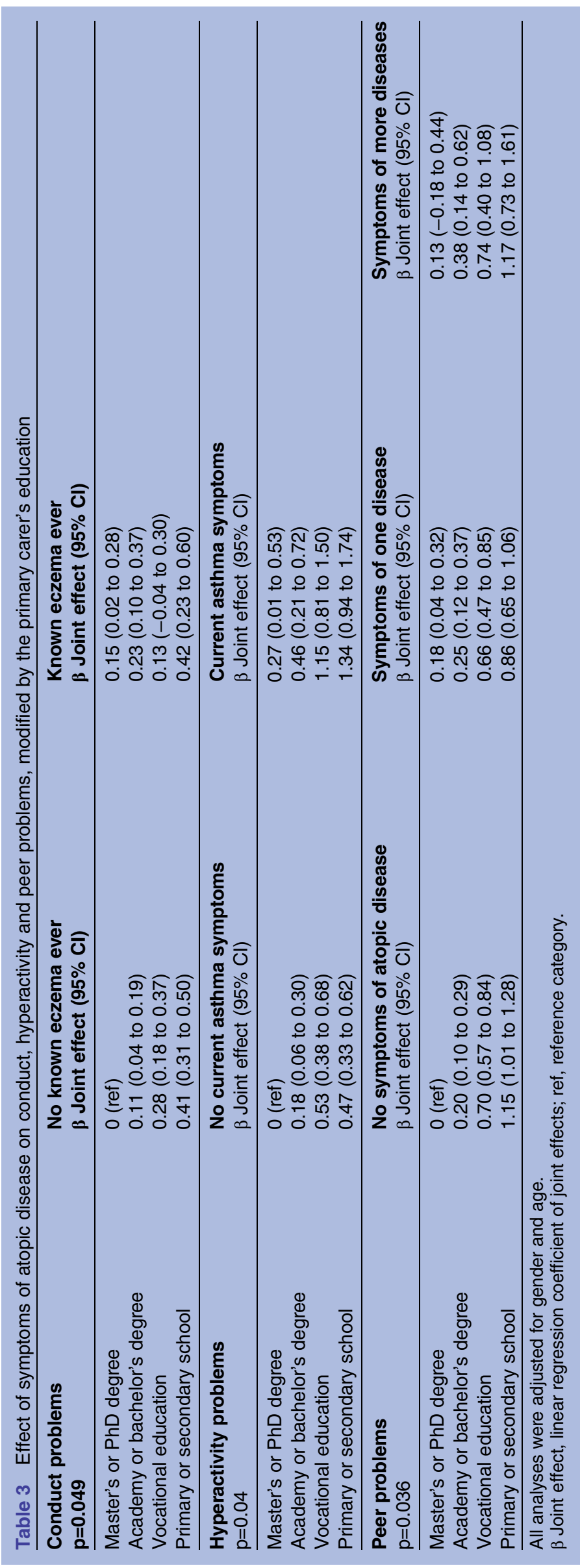

were highest for children with symptoms of more than one atopic disease. For most associations, we found no effect measure modification between atopic diseases and parental SEP. Atopic diseases added equally to the burden of mental health problems independent of SEP. Children with low SEP had higher raw SDQ scores, and thus children experiencing both atopic disease and low SEP will have the highest SDQ scores. Current asthma symptoms were associated with higher scores of hyperactivity problems among children with low compared with high parental SEP, while known eczema ever was only associated with conduct problems among children of primary carers with high but not low educational level.

To the best of our knowledge, this is the first investigation of the effect modification of parental SEP on these associations. Previously, a cross-sectional Polish study of students aged 18-25 years found greater differences in quality of life due to allergic diseases in students of low SEP than in those of high SEP. ${ }^{18}$

Our study confirms and extends previous research of atopic disease in association with mental health problems by addressing hay fever along with eczema and asthma, and by adjusting for parental SEP in a large population-based study of children at different

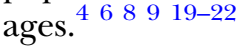

In contrast to our findings, a Danish report found no differences in child-reported overall mental well-being or parent-reported peer problems when comparing children aged 6-9 years with and without register information on doctor-diagnosed asthma or allergy. ${ }^{23}$ Two cross-sectional studies of children aged $5-15$ years ${ }^{19}$ and 14-16 years ${ }^{6}$ found increased risk of emotional and hyperactivity problems among children with asthma, whereas only one of these found an increased risk of conduct problems, ${ }^{19}$ and only one found no association with peer problems. ${ }^{6}$ These studies were population based with parent report or self-report of both asthma and mental health problems using SDQ. One study adjusted for maternal educational level and household income and was therefore particularly comparable with our study. ${ }^{19}$ Asthma was found to be associated with increased odds of mood, anxiety and internalising disorders, but not externalising or disruptive disorders in 917 -year-olds in the general community, as well as when adjusting for SEP. ${ }^{24}$ However, in high-risk service settings (juvenile justice, child welfare, mental health or substance treatment, and special education), asthma and mental health problems were highly prevalent but not associated. ${ }^{24}$

An American cross-sectional study in children aged 017 years found a history of eczema to be associated with increased odds of attention deficit hyperactivity disorder, depression, anxiety and conduct disorder compared with children without eczema. ${ }^{25}$ Another study of children followed up from birth until the age of 10 years ${ }^{7}$ found an increased risk of emotional and conduct problems among children with eczema, and no association with peer problems. Unlike the American 


\begin{tabular}{|c|c|c|c|c|c|c|c|c|}
\hline & \multicolumn{2}{|c|}{$\begin{array}{l}\text { Abnormal scores of } \\
\text { emotional problems }\end{array}$} & \multicolumn{2}{|l|}{$\begin{array}{l}\text { Abnormal scores of } \\
\text { conduct problems }\end{array}$} & \multicolumn{2}{|c|}{$\begin{array}{l}\text { Abnormal scores of } \\
\text { hyperactivity problems }\end{array}$} & \multicolumn{2}{|c|}{$\begin{array}{l}\text { Abnormal scores of peer } \\
\text { problems }\end{array}$} \\
\hline & OR (95\% Cl) & p Value & OR (95\% Cl) & p Value & OR (95\% Cl) & p Value & OR (95\% Cl) & p Value \\
\hline \multicolumn{9}{|l|}{ Eczema* } \\
\hline Known disease ever & $1.45(1.16-1.80)$ & $<0.001$ & $1.01(0.78$ to 1.31$)$ & 0.946 & $1.28(1.06$ to 1.55$)$ & 0.012 & $0.92(0.73$ to 1.16$)$ & 0.492 \\
\hline Current symptoms & $1.29(0.98$ to 1.71$)$ & 0.068 & $1.18(0.87$ to 1.60$)$ & 0.281 & $1.32(1.04$ to 1.68$)$ & 0.023 & $1.00(0.76$ to 1.33$)$ & 0.988 \\
\hline \multicolumn{9}{|l|}{ Asthma* } \\
\hline Known disease ever & 1.30 (0.98 to 1.72$)$ & 0.065 & 1.04 (0.75 to 1.45$)$ & 0.806 & 1.34 (1.03 to 1.73$)$ & 0.026 & $1.11(0.82$ to 1.49$)$ & 0.497 \\
\hline Current symptoms & 1.83 (1.44 to 2.33$)$ & $<0.001$ & $1.73(1.34$ to 2.24$)$ & $<0.001$ & 1.83 (1.49 to 2.24$)$ & $<0.001$ & 0.90 (0.69 to 1.18$)$ & 0.455 \\
\hline \multicolumn{9}{|l|}{ Hay fever* } \\
\hline Known disease ever & 1.44 (1.09 to 1.89$)$ & 0.010 & 1.25 (0.93 to 1.69$)$ & 0.145 & 1.15 (0.89 to 1.48$)$ & 0.285 & 1.49 (1.13 to 1.96$)$ & 0.004 \\
\hline Current symptoms $†$ & 1.62 (1.29 to 2.04$)$ & $<0.001$ & 1.25 (0.93 to 1.68$)$ & 0.136 & $1.44(1.14$ to 1.81$)$ & 0.002 & $1.14(0.88$ to 1.48$)$ & 0.328 \\
\hline Known atopic disease ever & & $<0.001$ & & 0.268 & & 0.042 & & 0.073 \\
\hline 1 vs none & 1.28 (1.03 to 1.59$)$ & & 1.20 (0.96 to 1.52$)$ & & $1.23(1.03$ to 1.48$)$ & & 1.27 (1.03 to 1.56$)$ & \\
\hline 2 or more vs none & 1.85 (1.34 to 2.55$)$ & & 0.97 (0.63 to 1.50$)$ & & $1.28(0.92$ to 1.76$)$ & & $1.10(0.75$ to 1.61$)$ & \\
\hline Current symptoms of atopic disease ${ }^{*}$ & & $<0.001$ & & $<0.001$ & & $<0.001$ & & 0.339 \\
\hline 1 vs none & $1.48(1.21$ to 1.81$)$ & & $1.52(1.22$ to 1.90$)$ & & 1.39 (1.16 to 1.66$)$ & & $0.90(0.73$ to 1.10$)$ & \\
\hline 2 or more vs none & 2.19 (1.61 to 2.97$)$ & & 1.60 (1.08 to 2.38$)$ & & 2.26 (1.69 to 3.02$)$ & & $1.17(0.82$ to 1.67$)$ & \\
\hline Primary carer's education $\ddagger$ & & $<0.001$ & & $<0.001$ & & $<0.001$ & & $<0.001$ \\
\hline Bachelor vs master & 1.45 (1.12 to 1.87$)$ & & 1.34 (1.01 to 1.77$)$ & & $1.32(1.07$ to 1.64$)$ & & $1.33(1.01$ to 1.75$)$ & \\
\hline Vocational vs master & 1.77 (1.34 to 2.32$)$ & & 1.78 (1.32 to 2.38$)$ & & 2.04 (1.62 to 2.55$)$ & & 2.89 (2.21 to 3.78$)$ & \\
\hline School vs master & 2.13 (1.62 to 2.79$)$ & & 2.39 (1.81 to 3.15$)$ & & 1.95 (1.55 to 2.44$)$ & & 4.87 (3.79 to 6.25$)$ & \\
\hline
\end{tabular}

Reference categories: known disease ever versus children without the atopic condition ever; current symptoms versus no current symptoms of the atopic condition. Reference level was 1.

*Analyses adjusted for gender, age and primary carer's educational level.

†For children aged 3 years, current symptoms of hay fever could not be reported.

$\ddagger$ Analyses adjusted for gender, age and symptoms of atopic diseases. 
study and our study, they found no association with hyperactivity problems.

Studies using other measurement tools have found similar associations between asthma and mental health problems. ${ }^{42021}$ Unlike our results, two Korean studies found no relation between internalising behaviour and eczema, or externalising behaviour and any of the diseases. $^{8}{ }^{9}$ This might be explained by their relatively small samples, lack of adjustment for potential confounders or cultural differences between Korea and Denmark.

Several hypotheses have been proposed to explain the mechanisms causing or underlying the relationship between atopic diseases and mental health problems. Stress due to suboptimal family functioning or adverse life events might be an underlying factor causing both conditions. Also, attention deficit hyperactivity disorder (ADHD) increases stress level, which in turn may trigger neuroimmunological pathways leading to eczema. ${ }^{26}$ Physical stressors such as prenatal smoking or inflammation could also be underlying or mediating factors. ${ }^{27-29}$ For example, inflammatory cytokines in eczema have been proposed to interfere with central nervous systems involved in ADHD. ${ }^{26}$ Parental mental health problems increase the risk of smoking and may cause atopic diseases in children who are already disposed to mental health problems. ${ }^{2}$ Sleeping problems early in life could be a mediator, as sleep is vital for brain development, psychological development and functioning. ${ }^{28}$ Finally, the impact of atopic diseases on quality of life and selfesteem may cause mental health problems through embarrassment at obvious symptoms and limited capability to engage in activities. ${ }^{30-33}$

An Australian study ${ }^{4}$ found atopic diseases to precede behavioural problems but not behavioural problems to precede atopic diseases, pointing towards the idea of a causal relationship rather than a matter of confounding.

It may be argued whether the relatively small mean increases in SDQ scores associated with atopic diseases found in this study constitute a clinical problem. Yet the odds of emotional, conduct and hyperactivity problem scores above the abnormal cut-offs are increased by 39$126 \%$ with current symptoms of one or two atopic diseases. This indicates a considerably increased risk of clinical mental disorders ${ }^{13}$ in children with atopic disease.

The difference in hyperactivity problems between children with and without current symptoms of asthma was larger in children with primary carers with short education compared with long education. This may be a spurious finding as this pattern was not observed with any of the other SDQ scales or atopic diseases. Hyperactivity constitutes an obstacle to academic learning. We may speculate that children with hyperactivity problems are more likely to receive medication or other treatment in families emphasising academic achievements. Hyperactivity may not pose a similarly large problem, and thus not be addressed to the same degree, in families placing less emphasis on book learning.

\section{Study strengths and limitations}

The strengths of this study include the large study population with four birth cohorts from a relatively homogeneous, urban population in respect to geographical characteristics, accessibility to healthcare free of charge, and regular health examinations of children. Second, our data came from a general health survey with no special focus on atopic diseases, mental health problems or SEP. Thus, participation was not likely to be affected by our study focus. Third, SEP was based on complete data from national registries, generally considered reliable and not subject to reporting bias. For self-report, we used instruments validated in various populations with good sensitivity, specificity and psychometric abilities. $^{13} 15$

Limitations include lack of information on parental atopy or mental health problems as underlying factors. Moreover, we were limited by the cross-sectional design based on parent report or self-report of diseases and symptoms. Imprecise measures are expected to result in an underestimation of associations. Misclassification not at random could, however, also result in an overestimation, if some persons were likely to over-report atopic symptoms and mental health problems. We would then also expect peer problems to be associated with atopic symptoms, which we did not find. Finally, the response rate was higher among children from well-educated, high-income families. Even though we weighted all analyses for non-response by detailed register information, selection bias is still a possibility. This bias would be expected to weaken the associations, as the study population presents more homogeneously than the background population.

\section{Conclusion and perspectives}

Children with symptoms of eczema, asthma or hay fever had higher scores of emotional, conduct and hyperactivity problems and were more likely to have abnormal scores of emotional or hyperactivity problems, compared with children without. Peer problems were only associated with current hay fever symptoms. For most associations, the burden of mental health problems due to atopic diseases added equally to the burden of mental health problems independent of parental SEP. Current asthma symptoms were associated with higher scores of hyperactivity problems among children with low compared with high parental SEP, while known eczema only was associated with conduct problems among children with primary carers with high but not low education.

While treating these children, healthcare professionals must be aware of comorbidity with mental disorders, as well as the possibility of poor mental health ranging in the 'normal' spectrum, calling for social or emotional support. Routinely performed child health examinations can play a key role in early detection of these disorders, and thereby minimise the impact of physical illness and poor mental health. 
Author affiliations

${ }^{1}$ Research Centre for Prevention and Health, The Capital Region of Denmark, Copenhagen, Denmark

${ }^{2}$ Department of Real World Evidence and Epidemiology, H. Lundbeck A/S, Valby, Denmark

${ }^{3}$ Department of Clinical Experimental Research, Rigshospitalet, Copenhagen, Denmark

${ }^{4}$ Faculty of Health and Medical Sciences, Department of Clinical Medicine, University of Copenhagen, Copenhagen, Denmark

${ }^{5}$ Department of Public Health, Aarhus University, Institute of General Medical Practice, Arhus, Denmark

${ }^{6}$ Department of Dermatology, Bispebjerg Hospital, Copenhagen, Denmark

${ }^{7}$ Faculty of Health and Medical Sciences, Department of Biomedical Sciences, University of Copenhagen, Copenhagen, Denmark

${ }^{8}$ Faculty of Medicine, Department of Health Science and Technology, Aalborg University, Aalborg, Denmark

Acknowledgements The authors thank Anne Sophie Gottlieb, Lars Ellebjerg, and their team at Public Health Copenhagen, who collected the data. Furthermore, they thank all participating children and parents. They specially thank statistician Rikke Kart Jacobsen from Research Centre for Prevention and Health for valuable methodological discussions

Contributors $\mathrm{LH}-\mathrm{H}$ and $\mathrm{CG}$ devised the conception and design of the study. $\mathrm{LH}-\mathrm{H}, \mathrm{AL}, \mathrm{CO}$, SFT and CG contributed to the acquisition, analysis and interpretation of the data. $\mathrm{LH}-\mathrm{H}$ was responsible for drafting of the manuscript, and LH-H, AL, CO, SFT, LTM and CG for critical revision for important intellectual content. All authors approved the final version of the manuscript for submission.

Funding This research received no specific grant from any funding agency in the public, commercial or not-for-profit sectors.

Competing interests http://www.icmje.org/coi_disclosure.pdfLH-H reports that she has been employed by $\mathrm{H}$. Lundbeck a/s in the period after drafting the prefinal version until submission of this manuscript.

Ethics approval The study was approved by the Danish Data Protection Agency. According to Danish legislation, approval from the Danish Health Research Ethics Committee System was not required, as the study was based on data from questionnaires and national registers.

Provenance and peer review Not commissioned; externally peer reviewed.

Data sharing statement No additional data are available.

Open Access This is an Open Access article distributed in accordance with the Creative Commons Attribution Non Commercial (CC BY-NC 4.0) license, which permits others to distribute, remix, adapt, build upon this work noncommercially, and license their derivative works on different terms, provided the original work is properly cited and the use is non-commercial. See: http:// creativecommons.org/licenses/by-nc/4.0/

\section{REFERENCES}

1. Baiardini I, Braido F, Brandi S, et al. Allergic diseases and their impact on quality of life. Ann Allergy Asthma Immunol 2006;97:419-28; quiz 429-30, 476.

2. Goodwin RD, Bandiera FC, Steinberg D, et al. Asthma and mental health among youth: etiology, current knowledge and future directions. Expert Rev Respir Med 2012;6:397-406.

3. Emerson RM, Williams HC, Allen BR, et al. How much disability does childhood atopic eczema cause compared to other common childhood problems. Br J Dermatol 1997;137(Suppl 50):19.

4. Alati R, O'Callaghan M, Najman JM, et al. Asthma and internalizing behavior problems in adolescence: a longitudinal study. Psychosom Med 2005;67:462-70.

5. McQuaid EL, Kopel SJ, Nassau JH. Behavioral adjustment in children with asthma: a meta-analysis. J Dev Behav Pediatr 2001;22:430-9.

6. Alvim CG, Ricas J, Camargos PA, et al. Prevalence of emotional and behavioral disorders in adolescents with asthma. J Bras Pneumol 2008;34:196-204.

7. Schmitt J, Apfelbacher C, Chen CM, et al. Infant-onset eczema in relation to mental health problems at age 10 years: results from a prospective birth cohort study (German Infant Nutrition Intervention plus). J Allergy Clin Immunol 2010;125:404-10.

8. Chang HY, Seo JH, Kim HY, et al. Allergic diseases in preschoolers are associated with psychological and behavioural problems. Allergy Asthma Immunol Res 2013:5:315-21.

9. Park J, Kim BJ, Kwon JW, et al. Patterns of psychosocial adaptation and allergic disorders in Korean schoolchildren. Int Arch Allergy Immunol 2011;154:249-57.

10. Hammer-Helmich L, Linneberg A, Thomsen SF, et al. Association between parental socioeconomic position and prevalence of asthma atopic eczema and hay fever in children. Scand J Public Health 2014;42:120-7.

11. Pedersen CB. The Danish Civil Registration System. Scand J Public Health 2011;39(7 Suppl):22-5.

12. Goodman R. The Strengths and Difficulties Questionnaire: a research note. J Child Psychol Psychiatry 1997;38:581-6.

13. Goodman A, Goodman R. Strengths and difficulties questionnaire as a dimensional measure of child mental health. J Am Acad Child Adolesc Psychiatry 2009;48:400-3

14. Niclasen J, Skovgaard AM, Elberling H, et al. SDQ: Normative SDQ Data from Denmark. http://www.sdqinfo.org/DanishNorms/ DanishNorms.html2013 (updated 22 March 2013)

15. Asher MI, Keil U, Anderson HR, et al. International Study of Asthma and Allergies in Childhood (ISAAC): rationale and methods. Eur Respir J 1995;8:483-91.

16. Williams HC, Burney PG, Pembroke AC, et al. The U.K. Working Party's Diagnostic Criteria for Atopic Dermatitis. III. Independent hospital validation. Br J Dermatol 1994;131:406-16.

17. Särndal C-E, Swensson B, Wretman J. Model assisted survey sampling. New York: Springer-Verlag, 1992.

18. Pawlinska-Chmara R, Wronka I, Marchewka J. Effect of socio-economic status on quality of life in people affected with respiratory allergy. Adv Exp Med Biol 2013;788:385-92.

19. Calam R, Gregg L, Goodman R. Psychological adjustment and asthma in children and adolescents: the UK Nationwide Mental Health Survey. Psychosom Med 2005;67:105-10.

20. Feitosa CA, Santos DN, Barreto do Carmo MB, et al. Behavior problems and prevalence of asthma symptoms among Brazilian children. J Psychosom Res 2011;71:160-5.

21. Goodwin RD, Robinson M, Sly PD, et al. Severity and persistence of asthma and mental health: a birth cohort study. Psychol Med 2013:43:1313-22.

22. Lien $\mathrm{L}$. The association between mental health problems and inflammatory conditions across gender and immigrant status: a population-based cross-sectional study among 10th-grade students. Scand J Public Health 2008;36:353-60.

23. Johansen A, Holstein BE., Databasen Børns Sundhed. Allergi hos indskolingsbørn. Temarapport og årsrapport. Børn indskolingsundersøgt i skoleåret 2014/2015. København: Databasen Børns Sundhed og Statens Institut for Folkesundhed, SDU, 2015.

24. Goodwin RD, Hottinger K, Pena L, et al. Asthma and mental health among youth in high-risk service settings. J Asthma 2014;51:639-44.

25. Yaghmaie P, Koudelka CW, Simpson EL. Mental health comorbidity in patients with atopic dermatitis. J Allergy Clin Immunol 2013;131: 428-33.

26. Buske-Kirschbaum A, Schmitt J, Plessow F, et al. Psychoendocrine and psychoneuroimmunological mechanisms in the comorbidity of atopic eczema and attention deficit/hyperactivity disorder. Psychoneuroendocrinology 2013;38:12-23.

27. Goldbeck L, Koffmane K, Lecheler J, et al. Disease severity, mental health, and quality of life of children and adolescents with asthma. Pediatr Pulmonol 2007;42:15-22.

28. Schmitt J, Chen CM, Apfelbacher C, et al. Infant eczema, infant sleeping problems, and mental health at 10 years of age: the prospective birth cohort study LISAplus. Allergy 2011;66: 404-11.

29. Wright RJ, Rodriguez M, Cohen S. Review of psychosocial stress and asthma: an integrated biopsychosocial approach. Thorax 1998;53:1066-74.

30. Camelo-Nunes IC, Solé D. Allergic rhinitis: indicators of quality of life. J Bras Pneumol 2010;36:124-33.

31. Chamlin SL, Chren MM. Quality-of-life outcomes and measurement in childhood atopic dermatitis. Immunol Allergy Clin North Am 2010;30:281-8

32. Everhart RS, Fiese BH. Asthma severity and child quality of life in pediatric asthma: a systematic review. Patient Educ Couns 2009;75:162-8.

33. Lewis-Jones S. Quality of life and childhood atopic dermatitis: the misery of living with childhood eczema. Int J Clin Pract 2006;60:984-92. 